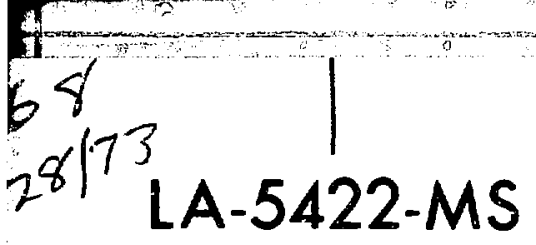

INFORMAL REPORT

A Versatile Rock-Melting System for the Formation of Small-Diameter Horizontal Glass-Lined Holes 
This repont was prepared as an wccount of work sponsored by the Uivited States Government. Neither the United States nor the United States Atomic Energy Commission, nor any of their employees, nor any of their comtractors, subcontractors, of their employees, makes any warranty, express or implied, or assumes any legal liability or responsibility for the accuracy, com. pleteness or usefutness of any information, appatatus. produst or process disclosed, or sepresents that its use would not infringe privately owned rights.

In the inierest of prompt distribution, this LAMS re. port was not edited by the Jechnical Information staft.

Printed in the United States of America. Availabie from

Nationat Technical Information Service

U. S. Oepurtment of Commesce 52p5 Dort Royal Road

Springtiald, Virginio 22151

Price: Printed Capy \$4.00; Microtiche $\$ 0.95$ 
LA.5422.MS

Informal Report

USC. 38

ISSUED: Ortaber 1973

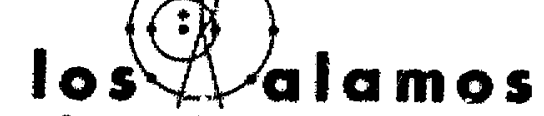

selentifle laboratory

of the University of Californic

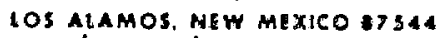

1

\section{A Versatile Rock-Melting System for the Formation of Small-Diameter Horizontal Glass-Lined Holes}

by

D. L. Sims

Work supported in part by a grant from the National Science Foundation. Research Applied to Notional Needs (RANN).

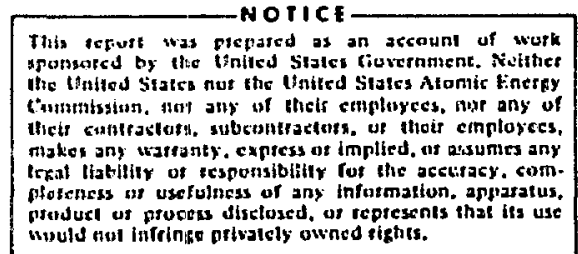




\section{CONrEMts}

I. Introduction 1

A. Program matory 1

B. Strali-Dianeter Horkintal subterzene Syater

I2. Syatern Dexcription 5

III. Sumary of Systen Specifications 9

xv. Dancription of LAst-Developed and Conmerclaliy
Avatiabla subccmponent:

A. General 9

D. Deseription of Components 9

v. Development Progran 12

A. Versatility of pale porming Assembly 12

2. Development of Ateitude-Control Sensors 13

C. Examples of Deviation Sensars 13

D. Alignnent control Seiction (ACs) 15

vi. Operations 16

vII. Conclustons and Discusation 17

APPENDIX

Analyais of Proposed Alignment Control seheme 20 
A VERSATILE ROCK-HELTING SYSTEN FOR THE FORMATION OF SHALL-DIAMETER HORIZONTAL GLASS-LINED HOLES

by

D. L. Sins

\section{ABSTRACT}

Rock-melting penetrators with diameters ranglng from $50 \mathrm{~mm}$ (a) in.) to 76 mon ( 3 in.) have reached a stage of development at the Los Alamos Scientile Laboratory (LASL) which suggests that these devices are ready for practical application. prototype refractory metal penetrators have formed glass-cased vertical holes of $26 \mathrm{~m}$ ( $92 \mathrm{ft})$ in a single run, and horizontal holes with diameters up to $227 \mathrm{~mm}(5 \mathrm{in.})$ are expected in the near future. These small horizontal holes can be usied for underground utility condites, for high-explosive shot emplacement; and as drainage holes to stablilze road suts or embankments.

Design coneepts and preliminary specifieations are described fer a subterrene system that forms small-diameter horizontal holes in rock by melting and simultaneously lines the hole with glassy rock malt. Host components of the system are comorcialiy avaliable. Deviation sensors and alignment-control units car be added to ensure that the holes are straight. The design and operation of this subterrene systen are degcriber and proposed development. approaches for the hole-forning assembly are discussed.

\section{INTRODLCTION}

\section{A. Progran History}

Rock-melting penetrators (Subterrenes) are under development at the Los Alamos Scientific Laboratory (LASL) to produce self. supporting glass-iined holes in roek and soil (Fig. 1) by progressive melting rather than by chipping, abrading, or spaliing. ${ }^{1}$ Rocks and ooils melt at temperatures that are relatively high: comon igneous rocks at $\sim 1500 \mathrm{~K}$, almost at the melting temperature of ateel $(2500$ to $1800 \mathrm{x})$. Thus, the melting penetritors must utilize refractory metals such as molybdenum (MO) and tungsten (w), which melt at 2880 and $3650 \mathrm{~K}$, respectively, and which, in addteton, have low creep rates at the rock-melting temperatures.

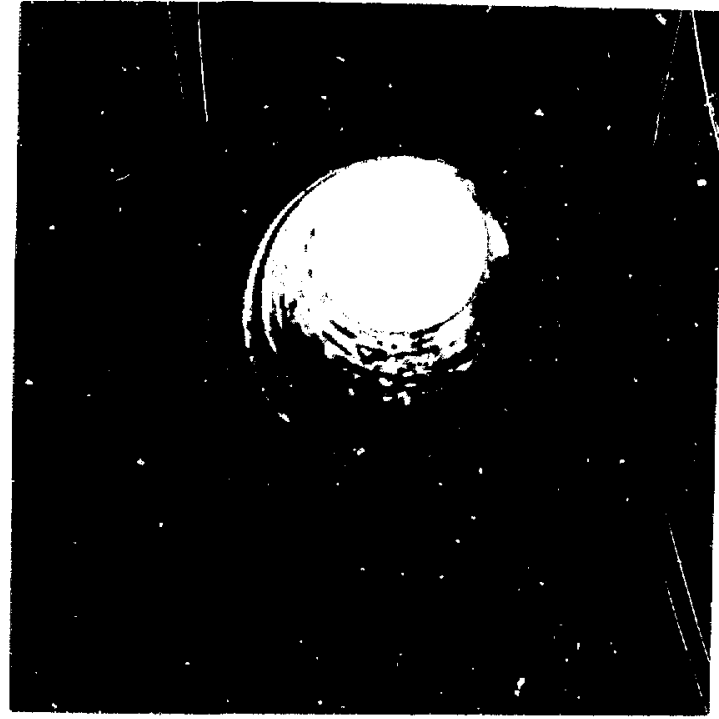

Fig. 1. Glass-lined hole melted in laboratory specimen of tuff. 
Excavation by rock- and soil-nelting offers potentially new and novel solutions to the three major areas of the excavation process:

- Making the hole or breaking up the rock.

- Providing structural support for the bore hole.

- Removing or displacing the debris or cuttings.

The liguid form of the rock- and soil-melt produced by a heated penetrator introduces new solution concepts into the latter two areas:

- The liquid melt can be formed into a glass lining to seal or support the walls of the bore hole, and

- Any excess liquid melt can be chilled and formed into glass rods, glass pellets, or rock wool (Figs. 2 and 3): or used to form a glass-cased core that can be removed by present wire-line methods.

The liquid melt produced by soil- and rock-melting techniques offers the potential of a complete systems approach to the processes of hole making, tunneling, and excavation. The LASL development program in rock- and soil-melting techniques has already demongtrated in laboratory and field tests an attractive advancement in practical excavation technology for the production of short, horizontal, small-diameter holes. This experience has been partially developed through the extensive testing of meltingconsolidating penetrators ${ }^{2}$ (MCPs). The tests consisted of:

- Melting 50-mm (2-in.)-diam, glass lined drain holes in Indian ruins ${ }^{3}$ at Bandelier National Monument (Fig. 4).

- Melting a s0-man (2-in.)-diam glasslined vertical hole in Los Alamos voicanic tuff to a depth of $26 \pi$. $(82 \mathrm{ft})$ in a single run. ${ }^{4}$

- Melting a 50-mm (2-in.)-diam glasslined horizontal hole in Los Alamos volcanic tuff to a length of $16 \mathrm{~m}$ (50 ft) (Figs. 5 and 6 ).

- Meliing a sequence of $76-\mathrm{mm}(3-i n)-$. diam glass-lined holes in volcanic tuif in the laboratory (Fig. 7).

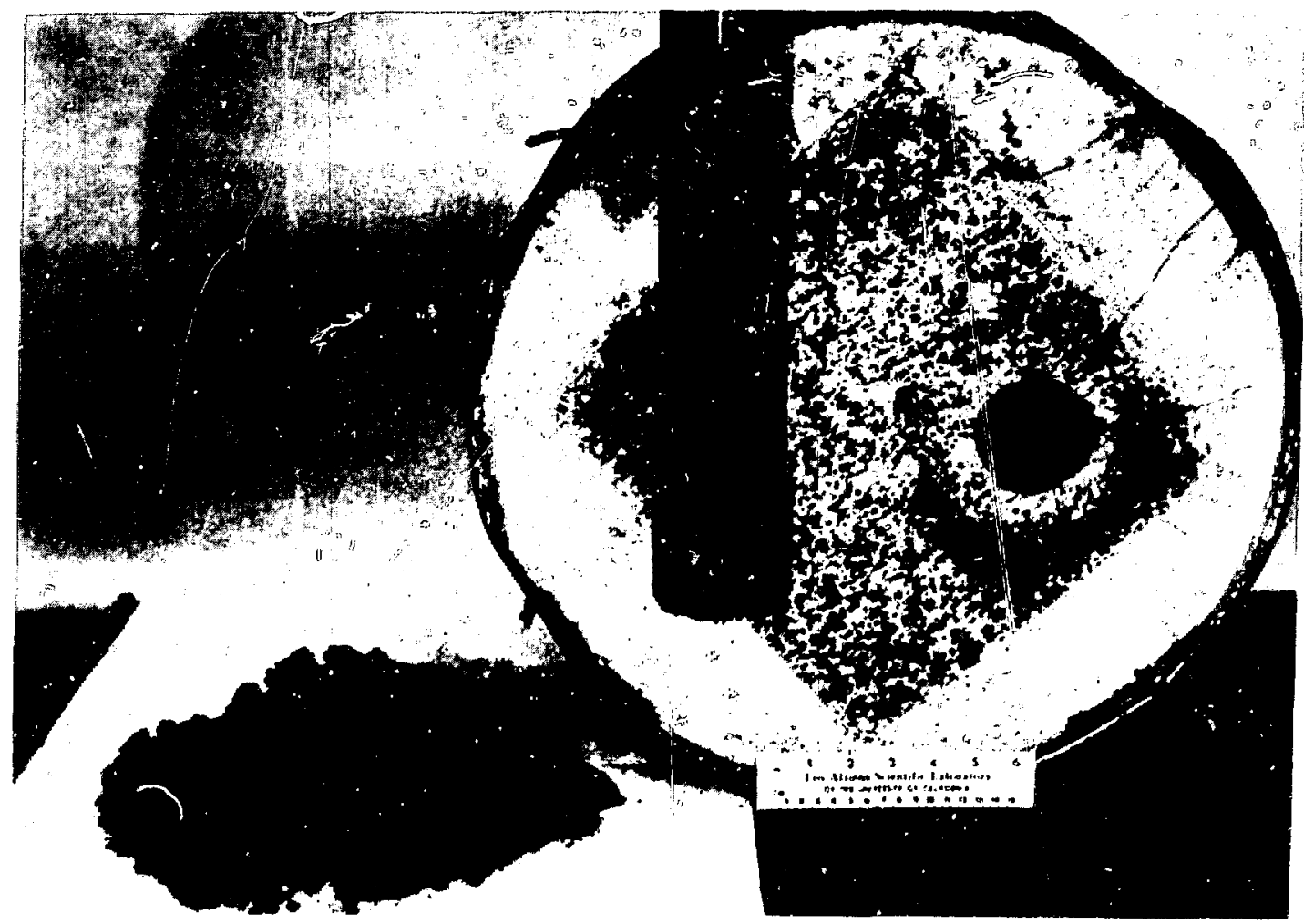

Fig. 2. Hole melted in granite specimen with an extruding penetrator. Note debris. 


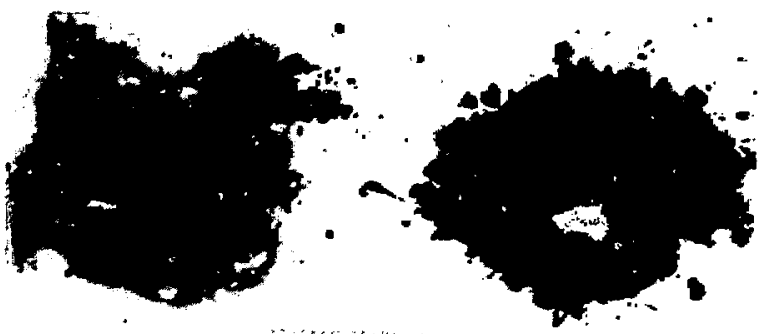

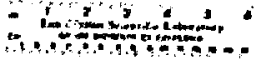

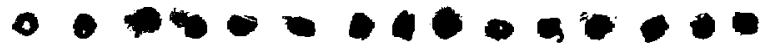

Fig. 3. Rock-wool and black glass debris from holes melted by extruding penetrator.

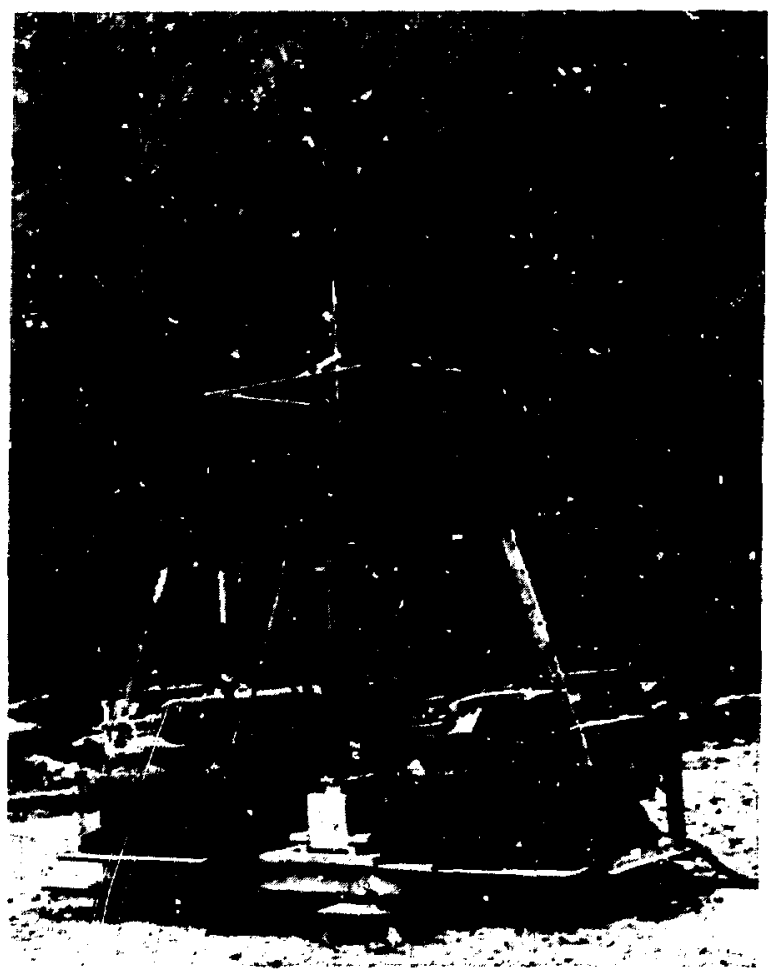

Fig. 4. Modular Subterrene field demonstration unit melting drain holes at Bandelier National Monument.

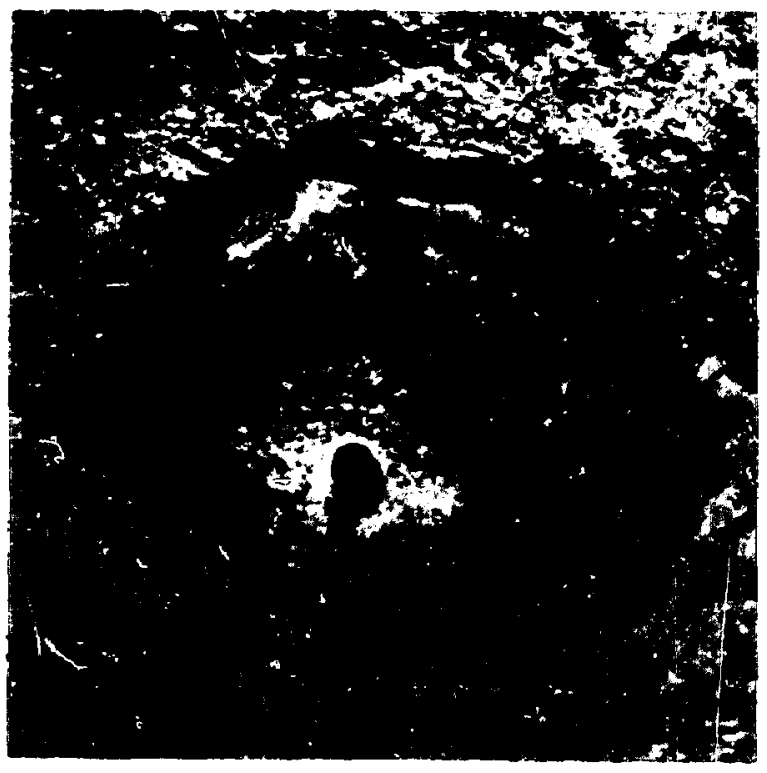

Fig. 5. Consolidating Subterrene Penetrator "holing through" a 16-m (50-ft)long horizontal hole.

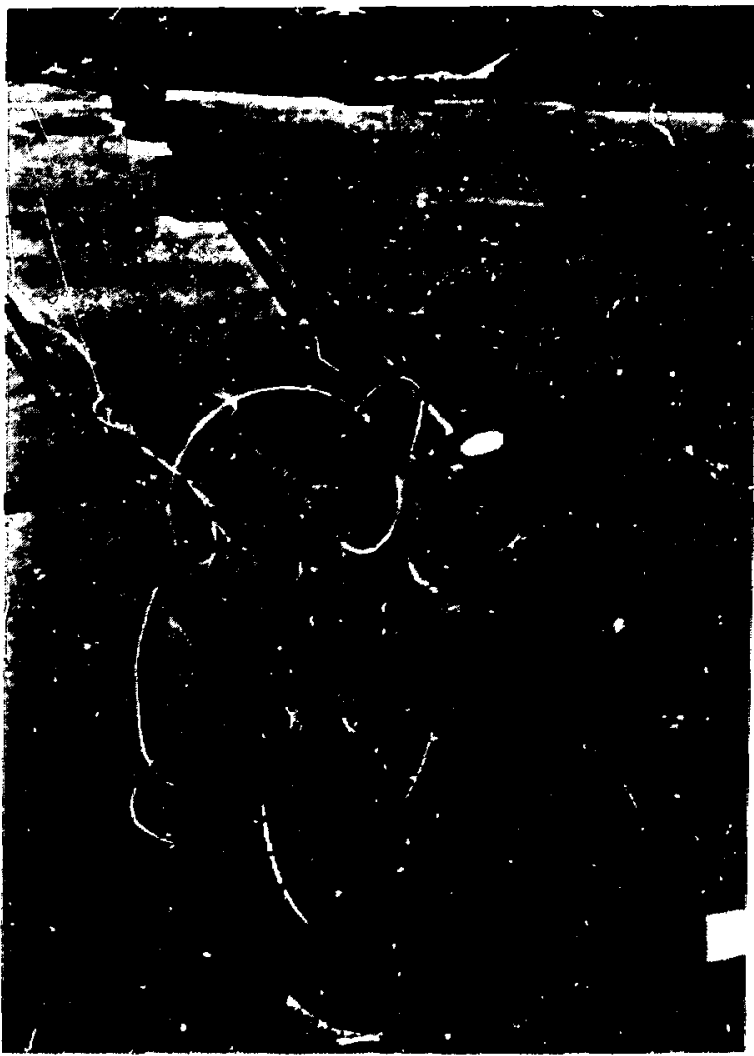

Fig. 6. Stem and service head in position to melt a 50-mm (2-in.)-diam horizontal hole. 


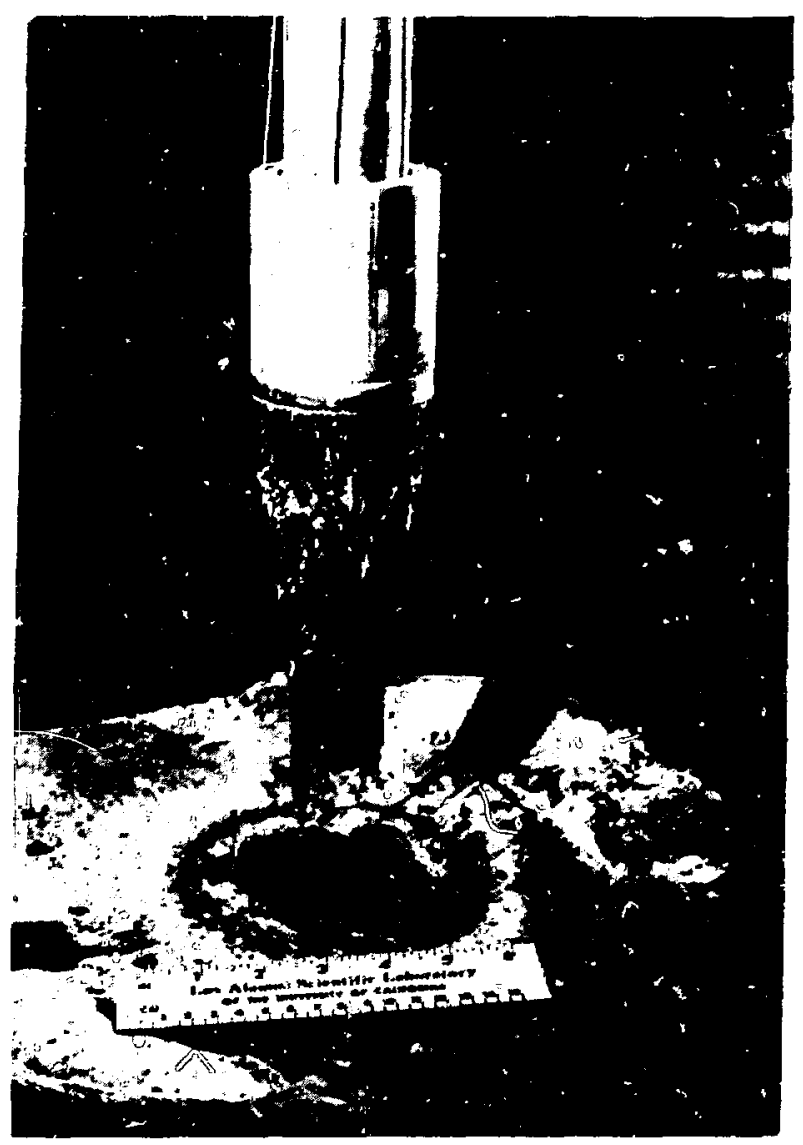

Fig. 7. Consolidating penetrator after melting a 76-mun (3-in.)-diam hole in Los Alamos tuff.

- Melting stable, 50-mm-diam glass-cased holes in shales, adobe, ard alluvium (Fig. B).

In addition, the prototype test program has developed a universal extruding penetrator (UEP) designed for hard, dense rock. 5 Tests with this unit have:

- Melted 66-mm (2.5-in.)-diam holes in basalt and granite (Fig. 2 ).

- Demonstrated the capability of talloring debrig for aifferent applications to meet varying debrisreturn systems (Fig. 3).

A modularized, mobile field-test and demonstration unit ${ }^{6}$ (Pig. 4) has been constructed, and was used sucoessfully for melting glass-1ined arainage holes ir the Hoor of Indian ruins at Bandeliez National Mcnument. This test rig will be used for additional field tests and for demonstrations of improved consolidating and extruding penetrators.

In addition, LASL is currently developing a 114-mm (4.5-in.)-diam, consolidating, coring penetrator that will produce a $63-\mathrm{mm}$ (2.5-in.)-diam glass-encased core.

\section{B. Smal1-Diameter Horizontal Subterrene Si'stem}

The coring capability for the subterrene, together with the commercial needs for horizontal holes for underground power 1 ines 7,8 and a review of requests for information on the rock-melting subterrene, has prompted the preparation of preliminary design concepts and specifications for a horizontal Subterrene capable of melting glass-lined, 76-mm (3-in.)-diam holes to lengths of ' $50 \mathrm{~m}$ (165 ft) with sufficient accuracy for most commercial applications. Horizontal glasslined holes of this diameter and length coula be useful as:

- Glass-lined arain holes for subsided mines.

- Glass-1ined drain holes through diked areas to accelerate drainage after flooding.

- Injection holes for burning mines.

- Sealed, glass-1ined inspection holes in mine faces or in dam abutments.

- Sealed, glass-lined inspection holes in suspected pollution areas.

- Underground utility conduits for telephone, gas, water, and television ines.

- Glass-Iined holes for high-explosive shot emplacement.

- Drainage holes to stabilize road cuts and embankments.

System descriptions, preliminary design concepts, and detail component descriptions are presented in the following sections, along with indications of additional development programs required to provide subsystems that are not yet available for this versatile horizontal holemelting device. Such a device will also 


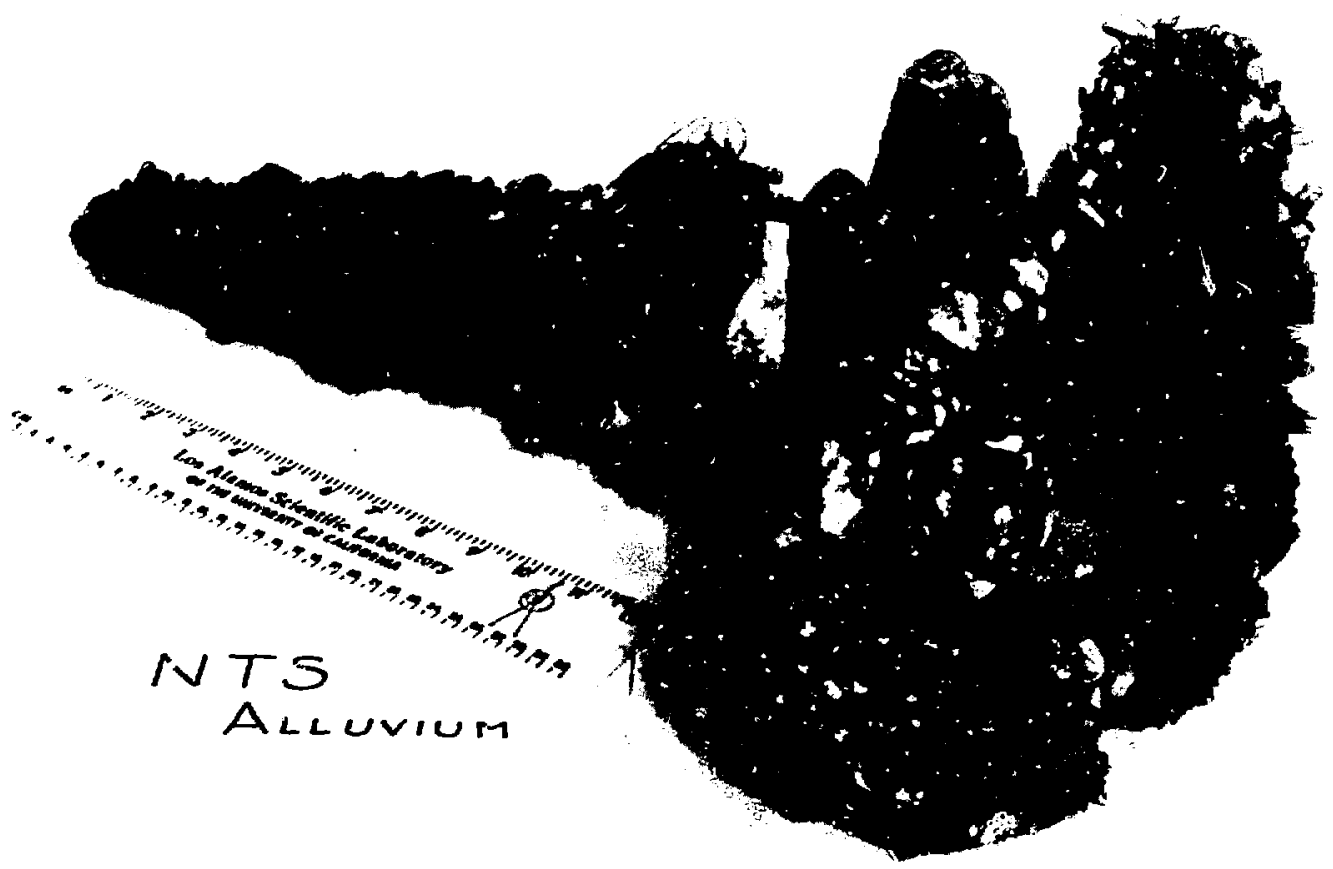

F'ig. 8. External surface of glass-lined hole melted in dry alluvium.

provide nevessary and valuable information for the development of the Geoprospector system."

\section{SYSTEM DESCRIPTION}

The comporents of the proposed smalldiameter horizontal subterrene system, depicted in Pig. 9, are similar to those of the modularized rock-melting subterrene demonstration unit shown in Fig. 4. These components include:

- A stem advancer, Fig. 10, that will continuously advance the stem by use of two independent hydraulic cylinders and remotely operated stem clamps.

- A dual-tube stem consisting of a flush outer steel tube, coupled in sections, and an insulated inner copper tube. These tubes provide the electric-power conductors

\footnotetext{
"See Ref. 7, p. 19, for a brief description of this continuously coring tunnel prospecting device.
}

to the heated penetrator, circulate coolant to the hole-forming assembly (HFA), and provide a force path to transfer the thrust to the advancing melting penetrator.

- Circulating, compressed-air coolant. to cool the stem, chill the glass-hole lining, and form small glass pellets (or rock wool) from the excess melt produced by a UEP. This excess melt debris is carried to the surface and ducted through the service head into separating and collecting station. The return coolant from a consolidating penetrator is ducted directly into the ambient air.

\section{- A guick-disconnect service head,}

Fig. 11, that connects the operational lines to the stem (i.e.. electric power for the penetrator, coolant air for glass-forming and debris removal, and sensor and instrumentation leads).

- The HFA (hole-forming assembly),

Figs. 12 and 13 , which is selected to fit the job raquirement, can be assembled interchangeably from the following subcomponents: 


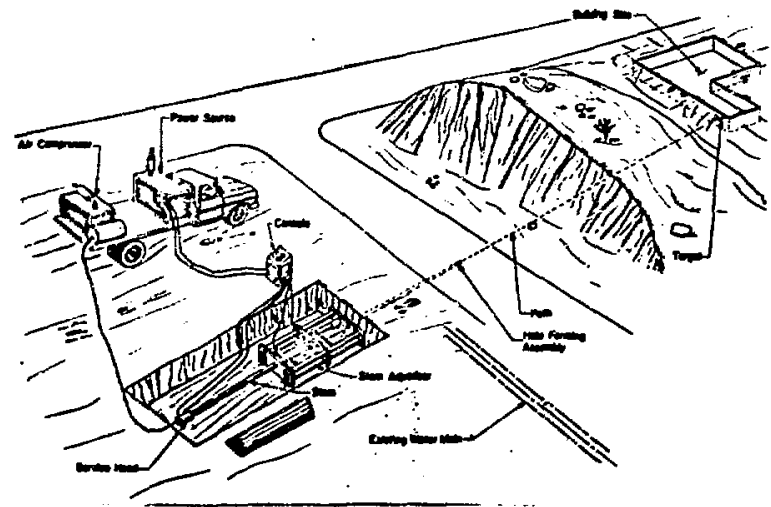

F1g. 9. Horizontal subterrene melting a water aervice hole.

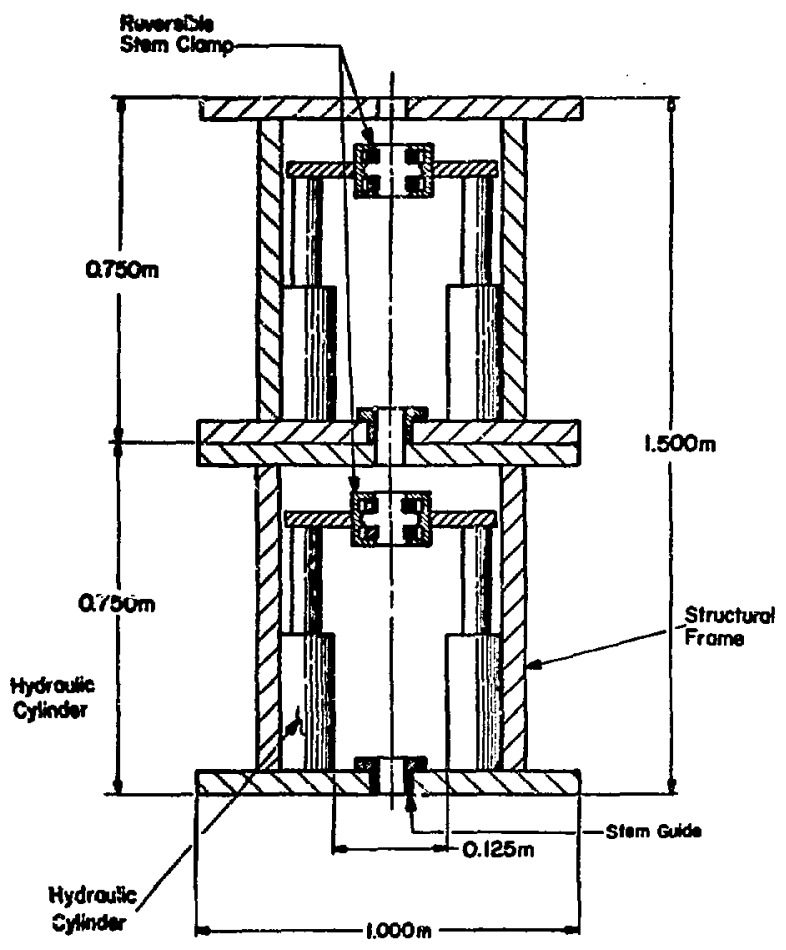

Fig. 10. Small-diameter horizontal subterrene stem advancer.

- A heated penetrator, to melt rock or soil: A relting consolidating penetrator (MCP)? Fig. 14, is used in loose solls, alluvium, and low-density rock, and forms a glass lining; whereas a universal extruding penetrator (UEP) ${ }^{5}, \mathrm{Fig}, 15$, is used in dense or hard rock and produces rock debris.

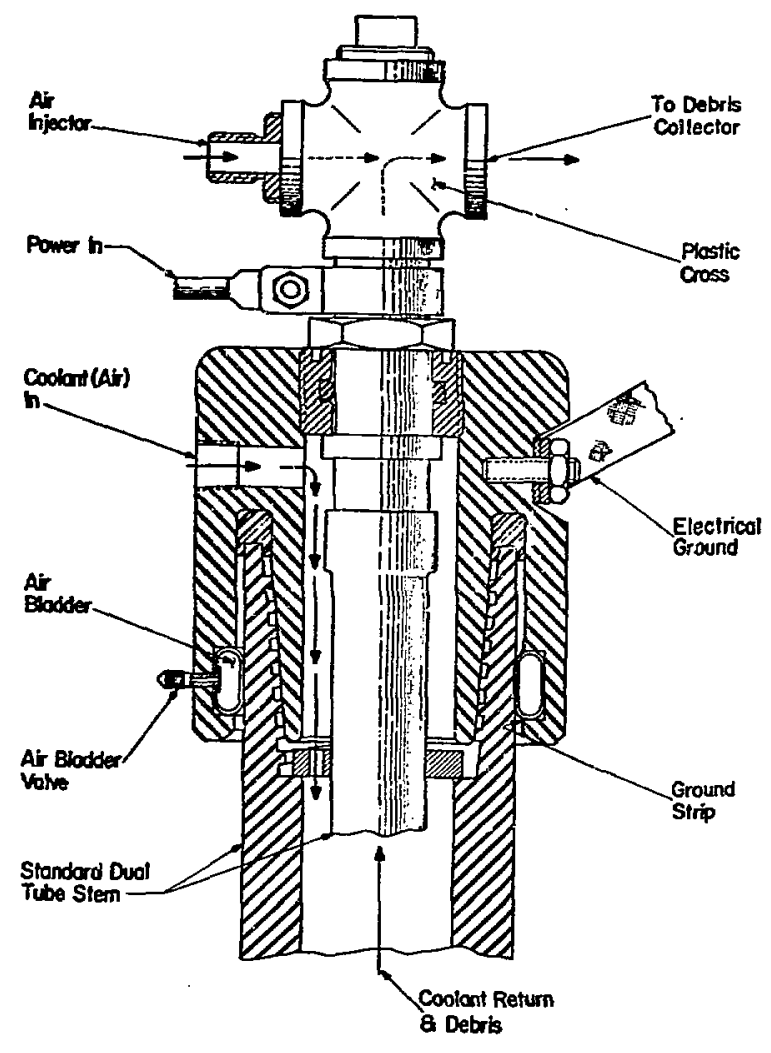

Eig. 11. Quick-disconnect service head.

- A glass former, attached directly to the penetrator, chills and forms the glass hole lining from the liquid melt. For the extruding penetrator, this unit also contains the components to chill the extrudate and to process the excess melt into removable debris.

- A centralizer,to hold the HFA on course.

- An alignment control section (ACS), to return the HFA to course when deviation is detected. The controlling force is oriented and applied from the surface control console.

- A deviation sensor (DS) or deviation indicator (DI), detects deviation of the HFA from the projected center line of the hole. Signals from the DS or DI are processed and displayed on the control console. The HFA can se made up in a variety of 


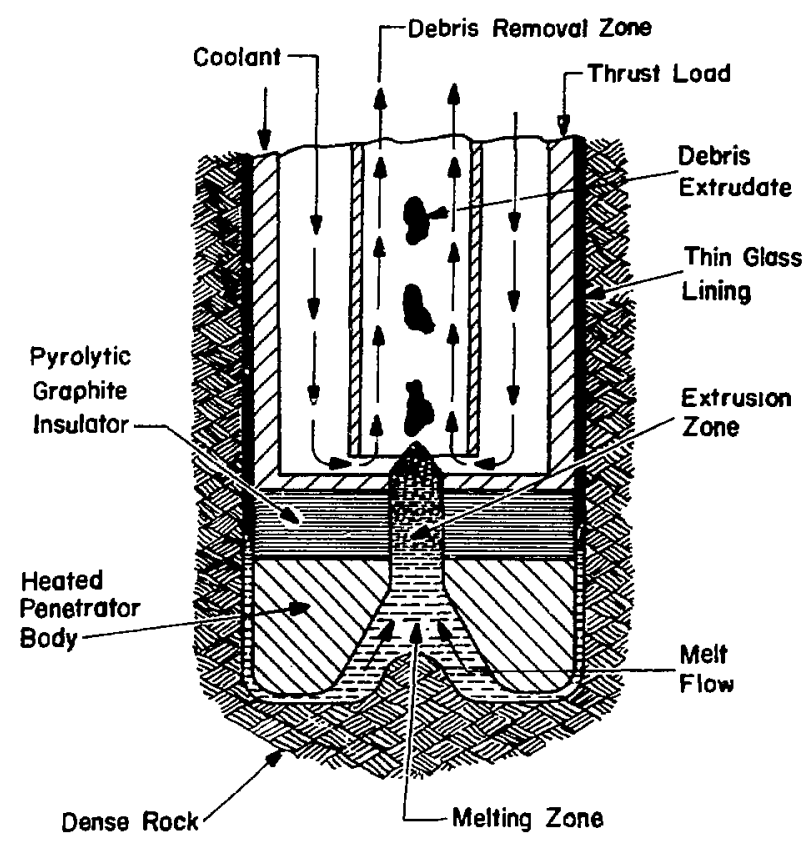

Fig. 15. Extruding penetrator for dense rock. configurations, as indicated in Fig. 12, to achieve the needed straightness for a given job.

- A complement of service units are needed to furnish electric power to the penetrators, sensors, and instrumentation; coolant air to the stem and glass-former; and hydraulic power to the stem advancer and stem clamps (Fig. 16). The coolant-air supply also powers an air-oil intensifier for emergency stem advance and retraction.

- A single control and instrumentation console will be provided for the necessary electric power, hydraulic and air controls, and for displays. Sensor displays and alignment-correction indications will also be shown on the console so that one operator can supervise the melting of a straight hole.

Note that the proposed horizontal rockmelting excavation system which forms the glass-lined holes in place can be assembled from various subcomponents to produce holes of varying straightness. For example, the hole-forming assembly can:

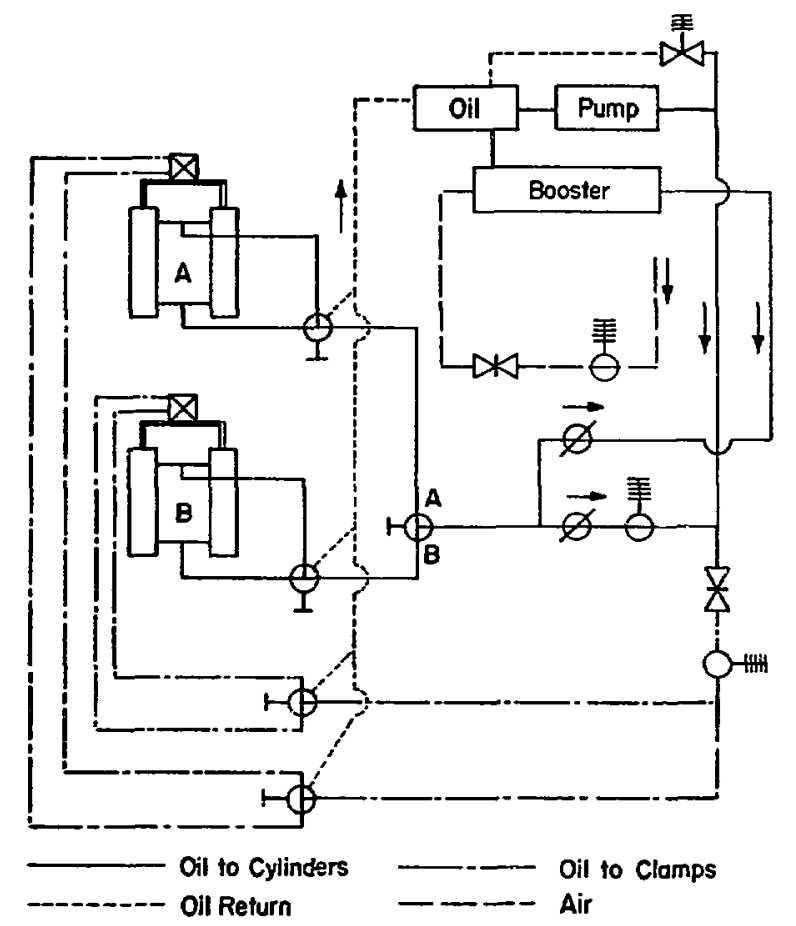

Fig. 16. Hydraulic and air-control circuits for operation of horizontal stem advancer.

- Melt an accessible, glass-lined hole under obstructions or structures such as roads, highways, railroads, and canals where hole straightness is not a major factor. This can be accomplished with a simple HFA consisting of only a penetrator, glass former, and stem, as indicated in Fig. 12 (a).

- Melt a very straight, accessible, glass-lined hole from an established point to intersect a target point with a maximum terminal deviation of two hole diameters or 1ess. This will require a HFA equipped with a deviation sensor, a surface-operated alignment-control unit, and a sensor signal that can be displayed on and monitored from the control console by the operator [Fig. 12 (d)].

The proposed system concepts, components, and specifications are detailed in the following sections. 
The following list sumnarizes the preliminary specifications for a horizontal hole-melting Subterrene system:

- Inside diameter of the glass lined hole, 76 m $(3$ in.).

- Hole-length capab1iity, $50 \mathrm{~m}$ (164 ft).

- Rate of penetration,

- For a melt-consolidating penetrator (MCP) in ioose alluvial soil up to $0.84 \mathrm{~mm} / \mathrm{s}(2 \mathrm{ln} . / \mathrm{m} / \mathrm{s})$.

- For a universal extruding penetrator (UEP) up to $0.42 \mathrm{~mm} / \mathrm{s}$ ( $1 \mathrm{in} . / \mathrm{min}$ ).

- The two penetrator types are interchangeable, are electrically powered, and use circulating eir for cooling and debris rewioval.

- The glass formers and hole sizers are integral parts of the penetrators.

- The maximum hole deviation is less than two diameters, but the system can be assembled in a simple version for less accurate operation.

- Deviation of the HFA from the projected hole center line is detected by the deviation sensor, and the amount of deviation is aisplayed on the control console.

- Directional control of the HFA is provided by a differential cooling system whose oferation is regulated at the control console for high accuracy. Lesser straightness will be controlled by simple stem rotation.

- The hydraulic stem advancer-retractor is capable of continuous motion and is provided with remotely operated stem clamps. Hole alignment can be set within the range of $\pm 0.25 \mathrm{rad}$ $(1.5 \mathrm{deg})$ from the horizontal.

- The advancing stem will be a dual tube to transmit power and coolant and for debris removal when required. The stcii will be flush externally and of sectioned lengths for ease of handiling.

- Melting power is estimated at $15 \mathrm{kw}$, and total available power should be $\sim 25 \mathrm{~kW}$.

- A quick-disconnect service head is included.

- The single control console will incorporate controls for air supply, hydraulic and electrical power; HFA deviation and amount of applied directional control; and instrumentation displays.

- The service units to be included are:
- Air compressor.

- Alternating-current generator, engine-driven.

- Alternating current-to-direct current converter.

- Bydralilic pump, motcz-driven.

- Ajz-0i2 hydrajilc booster.

- Light truck for mobility.

- Service leads and hoses are supplied as required.

\section{DESCRIPTION OF LASL-DEVELOPED AND COMBERCIALLY AVAILHBLE SUECOMPONENTS}

\section{A. General}

This section describes components of the system that are either already developed or can be designed and assembled in a straightforward manner from comercially available products. The demonstration 519 for 50-ints (2-in.)-dian penetrators has had excellent results in initial runs. Much of this simple, inexpensive sodular rig (Fig. 4), can be used as the design base for the 76-mm (3-in.)-diam horizontal subterrene. Other components have been thoroughly tested both in the laboratory and in field-test rigs. The alignment accuracy of the demonstration rig is sufflcient for many anticipated uses of horizontal, glass-lined holes. Is fact, by intermittently rotating the stem and the HFA of 50-ma (2-in.)-dian subterrenes while meiting vertical (Fig. 17) and horizontal (Fig. 18) holes, bores were produced that were straight to considerably better than two hole diameters in $16 \mathrm{~m}$ of hole length.

\section{B. Description of Components}

Specifically, the proposed small-dianeter horizontal Subterrene system would consist of the components detailed below.

\section{Stem Advancer}

The stem advancer (Fig. 10) will

advance the stem continuously with two independent, twin hydraulic-cylinder units and remotely operated stem clamps. 


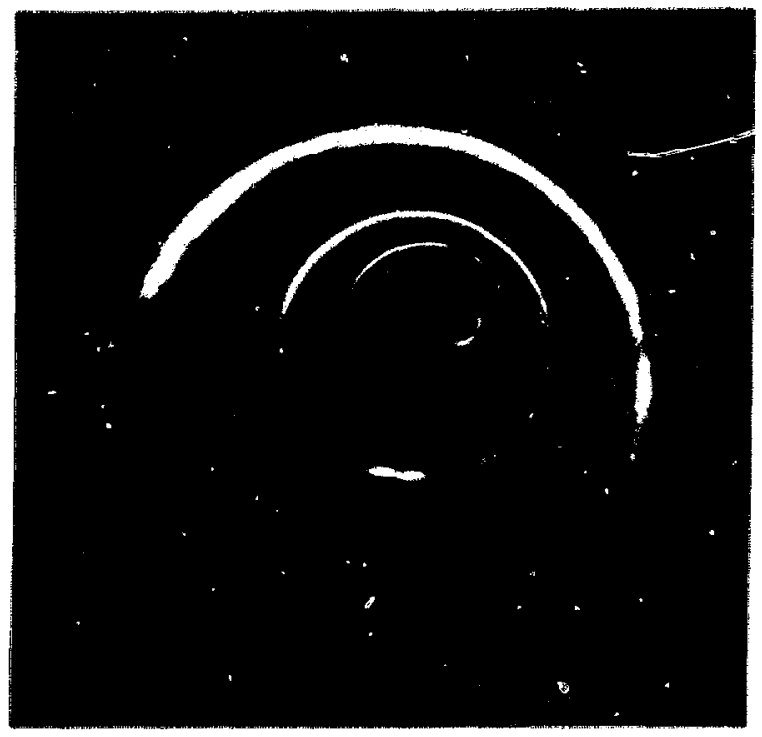

Fig. 17. Photograph showing tegree of straightnoss in a glass-lined vertical hole.

- Nomal operating pressurc vill be 6.5 upa $11000 \mathrm{psil}$ for an advancing load per cylinder pair of $20000 \mathrm{~N}$ (4550 1be) and a retracting pull of 28000 is $\left(63501 \mathrm{~b}_{\mathrm{f}}\right)$.

- Emergency operation will use four cylinders wich a maximum of $13.8 \mathrm{MPa}$ (2000 psi).

- The frame (head and base of each cylinder paifl will be adapted for fastening to anchor posts, and wil be rigid at the above loads.

- Retraction time of a cylinder pair, with normal operating pressure using the hydraulic pump only, will be $20 \pm 5 \mathrm{~s}$.

\section{Advancing Stem}

- The dual-tube advancing stem (Figs. 11 and 12) will be similar to that used on the moáularized, mobile rock-melting subterrene demonstration unit. 6

- The stem will be flush externally and slightly smaller in diameter than the HFA. The inner copper tube will have an inside diameter of $\sim 27.5 \mathrm{~mm}\left(1 \frac{1}{16}\right.$ in.).

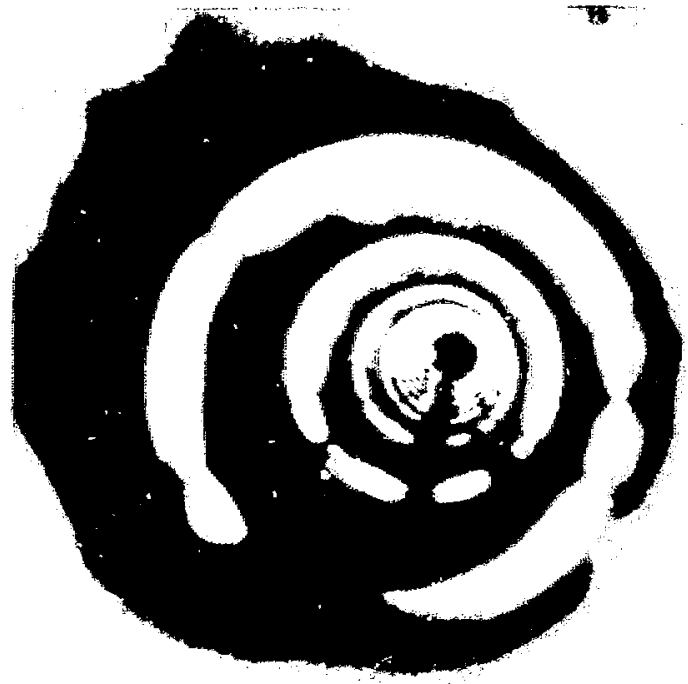

Fig. 28. Photograph showing degree of seraigheness in a glass-lined horizontal hole.

- The operating temperatures of the stem are estimated to be less than $600 \mathrm{~K}$. Waterials used in sten construction near the HFA will have an operating life of 3000 h at this tomperature. ndaitional stem sections will be constructed of conventional materials (low-carbon steel) and will operate at lower temperatures $(400 \mathrm{k})$.

- The stem will be assembled in lengths of $1.5 \mathrm{~m}(5 \mathrm{ft})$ and $3 \mathrm{~m}(20 \mathrm{ft})$.

\section{Serwice Head}

The service head (Fig. I1) will provide a quick disconnect (and connect) of the surface supply lines to the stem (electric power, coolant, instrumentation, and debris remova1).

\section{Hole-Forming Assembly (HFA)}

The hole-forming assembly (Fig. 12) for the simplified small-siameter horizontal Subterrene system would ie assembled from the following.

- A heated penetrator will be selected for the anticipated rock of soil to be 
encountered. Melting-consolidating penetratora 76 isn (3 1n.) in dianeter (Fig. 14) will be used for melting glass-lined holes in alluvium and low-denstty rock, and will be almilar in design to the consolldating penetrators that have been developed. Univeroal extruding penetrators, which are interchangeable with melting-coneolidating penetratore in the $\mathrm{EFA}$, are used for melting in dense or hard rock. The design and construction of this type penetrator 18 also well advanced. Both penetrators will produce jiass-1ined holes of the same dianeter.

- A glass former and hole glzer 18 attached directly to the penetrator. Because the melt is processed differently by the two types of penetrators, the glass former and hole sizer must be changed when the penetrator types are changed. The outside diameter varies with penetrator design, but is normaliy $0.15 \mathrm{ma}(0.005 \mathrm{in.})$ larger than the penetrator diameter (at operating conditions).

- A centralizer -- essentially a section af advancing stem with longitudinal Iibs bullt up to within 0.25 to $0.40 \mathrm{~mm}$ (0.010 to $0.015 \mathrm{in.})$ of the inside diameter of the finished glass lining -- is placed between the glass former-and-hole sizer and the forward end of the advancing stem.

\section{Service Units}

The gervice unitg required to operate the small-diameter horizontal subterrene are:

- $R$ skid-mounted air compressor rated at $200 \mathrm{l} / \mathrm{s}(44 \mathrm{cfm})$ at $825 \mathrm{kPa}$ (120 psi).

- A trallermounted, diesel-powered ac generator rated at $25 \mathrm{kH}$, with 60-cycle outputs of $17 \mathrm{kH}$ at $220 \mathrm{~V}$ and $8 \mathrm{kH}$ at $110 \mathrm{~V}$.

- A solid-atate ac-to-dc converter with $15 \mathrm{~kW}$ capscity, remotely controlled from the operator's console and powered by 60-cycle $220 \mathrm{~V}$.
- The hydraulic supply is a constantvolume vane pump with a 3.8-kw (5 hp) $220-\mathrm{V}$ 60-cycle motor. The output $180.15 \mathrm{l} / \mathrm{s}$ (2.4 gal/min) at $14 \mathrm{MPa}(2000 \mathrm{psi}$ delivery pressure.

- The emergency hydraulic supply is furnished by an air-oil booster that provides 0.25 \& (16 in. ${ }^{3}$ ) with a 300-mm (12-in.) stroke. The hydraulic pressure is $13.8 \mathrm{MPa}$ (2000 psi) from the 55-kPa (80-psi) air supply.

- Power, coolant, and hydraulic leads are of conventional field-service weight to hook up the separate units.

6. Control Console

The electric, hydraulic, and air controls needed to operate the small-diameter Subterrene system w11 be grouped on the console (Fig. 16), so that a seated operator can control all operations. Instrument displays on the control console will include:

- The advancing or retracting load on the stem, reading in $\mathrm{Pa}$ and $\mathrm{lbf} / \mathrm{in} .^{2}$

- The hydraulic pressure available for advancing or retracting, reading in $P a$ and $l b E / i n .2$

- The hydraulic pressure on the sterm clamps reading in $P a$ and $l b f / i n .2$

- The air pressure in use for cooling and debris removal, and the pressure available for the alr-oil, booster, reading in $\mathrm{Pa}$ and $\mathrm{ibf} / \mathrm{in}$.

- The advance rate of the stem, reading in $\mathrm{mm} / \mathrm{s}$ and in./min.

- The accumulated advance, reading in $m$ and $f t$.

- The amperage, voltage, and wattage of the heater circuit, and the heater resistance.

7. Mobilizing and Transport

The mobile small-dianeter horizontal Subterrene system is transported on a one-ton truck.

The maximum length of a small-diameter glass-1ined hole that can be successfully bored with this mininum system has not yet been determined. When increased hole length 
and accuracy are required, a deviation sensor (DS) and an alignment-control section (ACS) will have to be added to the HFA. Development of these units is discussed in the next section.

\section{DEVELOPMENT PROGRAM}

\section{A. Versatility of Hole-Forming Assembly}

The subsystems (see section III) of the small-diameter horizontal subterrene system are, with three exceptions, either already in use or are commercially available. The three exceptions are:

- A deviation indicator,

- A deviation sensor,

- An alignment-control section.

The deviation indicators and deviation sensor subsystems can be adapted from available instrumentation and electronics, but the alignment-control unit will require a development program and is unique to the proposed horizontal hole-forming system.

. These additional subsystems allow a planned programing of hole-forming assemblies (HFAs) for jobs requiring varying levels of hole straightness and completion accuracy. Desired levels of performance can be achieved by assembling HFAs in the following configurations:

Assembly A. A heated consolidating or extruding penetrator (depending on geology and density of the formation) is used with an advancing stem [Fig. $12(a)]$ to melt. e.g., horizontal, shallow surface drain holes; equipment-placement holes; and utility conduits having moderate tolerances for installation misalignment. The course of the melted hole is controlled by periodic partial rotation of the advancing stem to equalize deviations caused by eccentricity of the assembly.

Assembly B. A heated penetrator, centralizer, and advancing stem [Fig. 12(b)] can be used to extend the length of holes melted with alignment requirements similar to those of Assembly $A$. The centralizer holds the heated penetrator on course, allowing higher stem loads, increased penetration rates, and longer contralled penetration. Periodic partial rotation is again used to equalize deviations due to assembly eccentricity. The centralizer assists in the control of penetrators over longer and more accurate runs such as utility conduits for high-voltage supply and gravity-sewer connectors.

Assembly C. This system consists of a heated penetrator, centralizer, deviation indicator", operator signals, and advancing stem [Fig. 12(c)]. In addition to providing the increased hole-aligiment capability of Assembly $B$, the operator is alerted whenever the HFA deviates by a preset amount from the proposed hole center line. By indicating to the operator the quadrant of deviation (viewed down the hole) thi: operator may initiate a course correction by quadrant rotation of the advancing stem rather than by periodic partial stem rotation. Continued quadrant deviation would signal a mechanical cause, either a change in geologic formation (boulders) or stem deformations.

Assembly D. A heated penetrator, deviation sensor (or deviation indicator), alignment-control section, centralizer, operator signals, and audvancing stem [Fig. $12(d)$ ] are assembled. This unit can track the deviation of the HFA assembly from the projected center line of the hole in terms of azimuth and bearing, and display this information on the control console. The alignment-control section allows the operator to turn the HFA toward the projected hole center line. This assembly also allows the operator to follow and to control the HFA in a predetermined deviated path. Such positive control of the hole-forming assembly will increase the capacity of the smalldiameter horizontal subterrene system for

*The deviation indicator is used for quadrant deviation signal and control. 
following critical paths or intersecting sma11 targets.

\section{B. Development of Attitude-Control Sensors}

Several approaches to the development of sensors, deviation indicators, and alignment-control aystens are being investigated. The devidtion indicator (DI) shown conceptually in Fig. 19 will Elash a light on the control console to alert the operator that the hole-forming asaembly has deviated a predetermined amount in a given guadrant (viewed from the stem-advancer end). The signal is generated when the cantilevered section of the inner tube is contacted by the outer housing after a predetermined deflection. This approach is similar to that of a simple torque-srench indicator.

The development of a deviation sensor (Ds) can choose anong several possibilities:

- Laser optical systems are currently in use for aligning tunnel-boring machinez; however, although the HFA w111 probably deviate more than one diameter in a guidancecontrol cycle and although the use of a laser is therefore questionable, these systems will be reviewed for possible adaptation of the HFA.

- Inertial guidance systems are widely used for navigation and attitude-control systems. These systems will also be reviewed.

- Gyrostabilizers are extensively used for navigation, attitude control, and bore-hole surveying. 9-11 They will be reviewed for possible applicati $n$ for inclusion in the HFA. A preliminary review indicaites that hole size and length of time to melt a hole may restrict their use to attitude and directional control.

- Surface triangulation of a seismic source in the HFA may be a method to determine hole deviation. Results to date have not veen promising, but a state-of-theart review should reveal whether sufficient progress has been made to accurately track an HFA.
- Triaxial dc magnetometers are in use for attitude-sensing and navigation. In one current application 12,13 the device is following the path of a directional arilling tool and signals any deviations of a bore hole in conventional oil, gas, and water driling, or in guiding the drilling of life-support holes to trapped miners. A review of this system will determine its adaptability for HFA use.

\section{Examples of Deviation Sensors}

Two possibilities aiscussed above are used to illustrate the sensor section of the HFA, the surface display, and the operator's use of the aisplay to initiate corrective action (see Figs, 19, 20, and 21). Ar open-loop sensing and control system is considered adequate for the length of hole specifled in section III.

The relatively simple deviation indicator shown in Fig. 19 can alert the operator if the HFA is deviating ial a given quadrant. A section of the inner tube is built as an independent cantilever beam by using a fiexible bellows connection. Four contacts are placed around the inner tube with a small initial standoff clearance from the tube. Deflection of the outer housing, forced by hole deviation, will cause contact between the inner tube and one of the four contacts. closing of the contact will light up a corresponding signal on the control console. Corrective action can then be initiated either by rotating the advancing stem to equalize mechanical alignment, or by using an alignment-control section in the HFA. Physical orientation of the advancing stem is maintained by aligning and clamping fiducial protractors that are attached to the stem section at the stem advancer.

A triaxial magnetometer sensor can detect rotation of its axes relative to an initial orientation. Figure 20 shows schematically the use of a triaxial magnetometer as the deviation sensor for a 


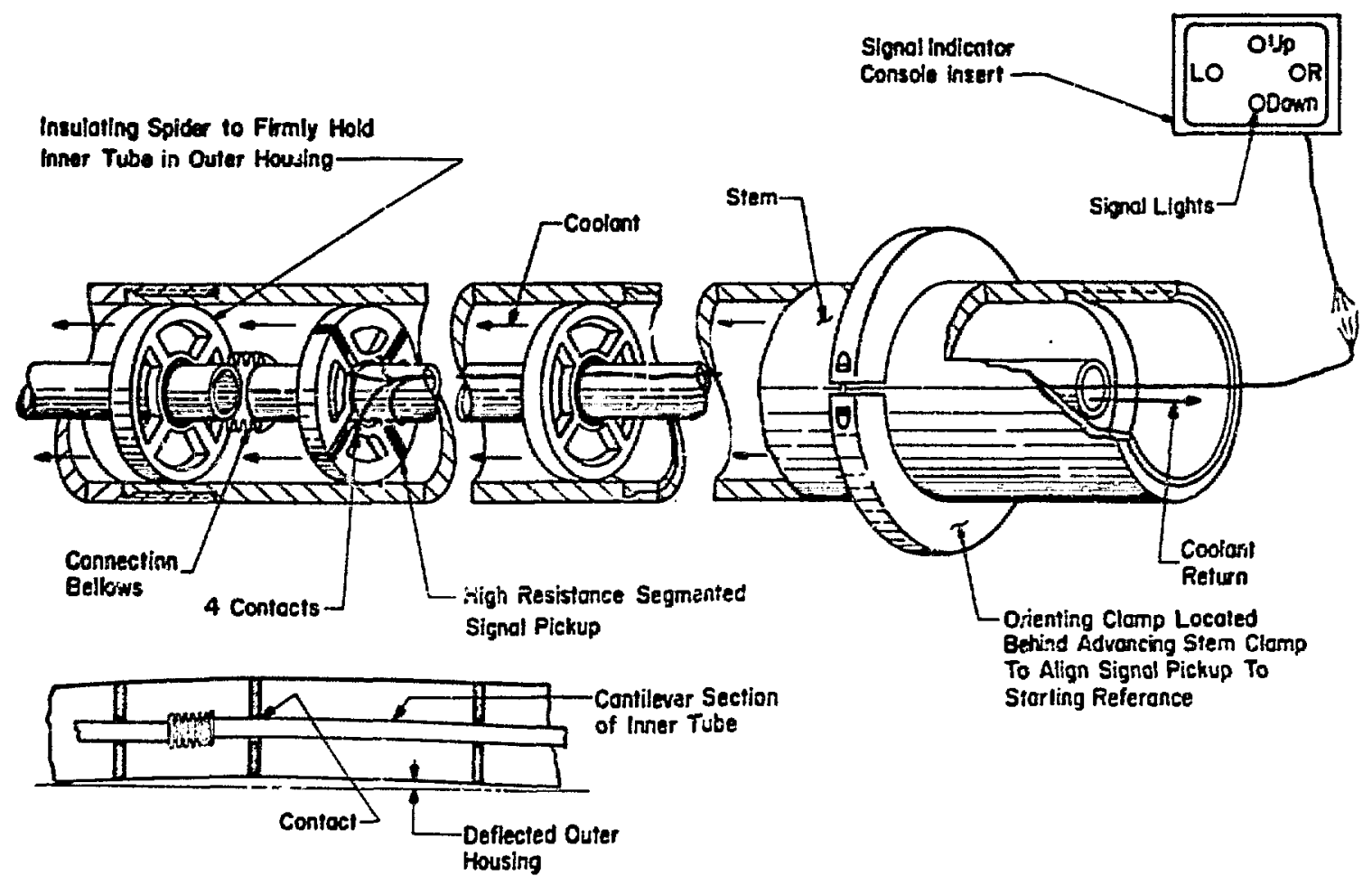

Fig. 19. HFA deviazion indicator.

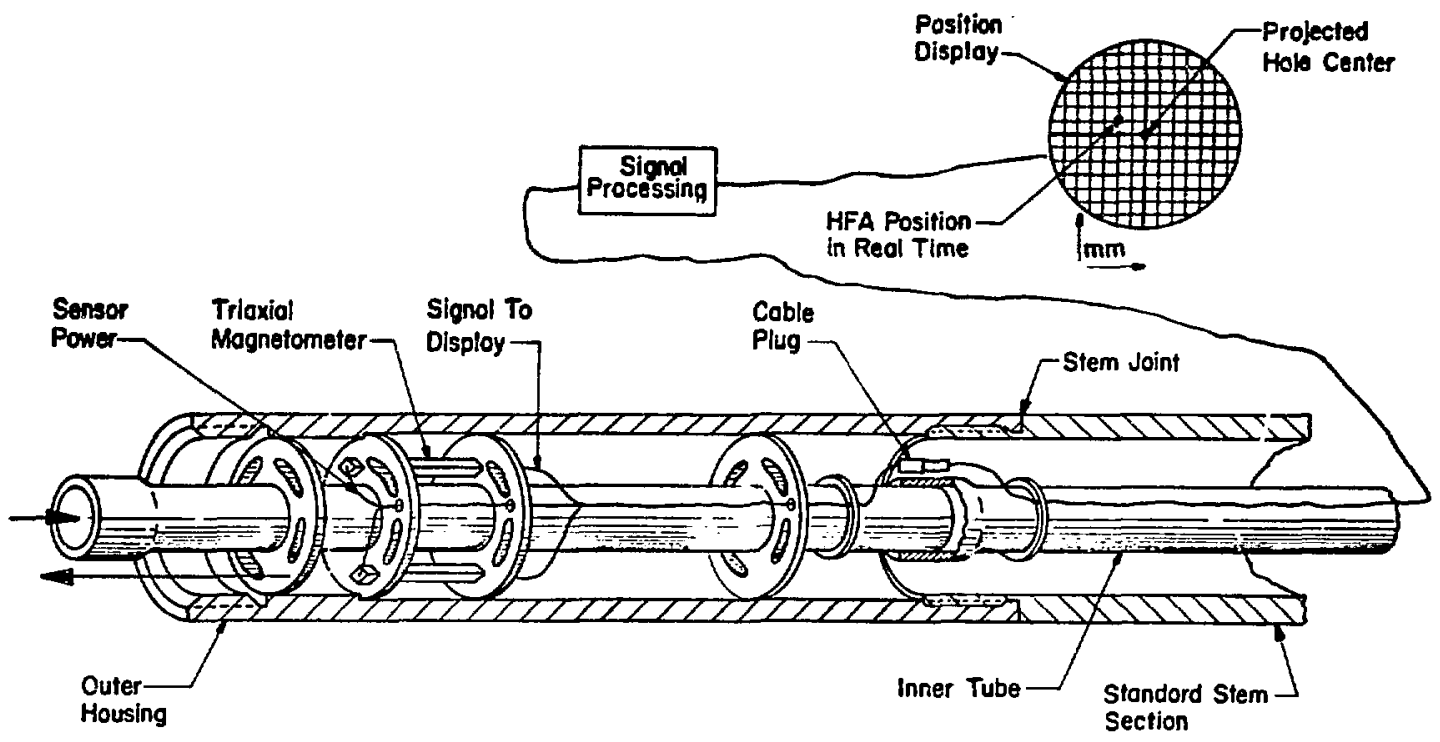

Fig. 20. Triaxial magnetometer deviation sensor. 
sma11-diameter horizontal subterrene. The power to the sensor and the return signali is carried in a multiple-charnel cable to a signal processor. After processing, the change in postion of the HFA is displayed on an oscilloscope screen in the control console. A computer can be used to plot continuously the excursions of the HFA from the hole center. However, penetration rates are eufficientiy slow to determine HFA excursions by hand-calculation (Eig. 21), eliminating computers and plotters.

\section{Alignment Control Section (ACS)}

One method of applying a realigning turning force to a heated penetrator while melting a hole is to selectively cool one

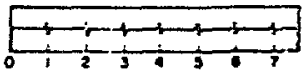

Aceomuleine Paratroiton in Muture

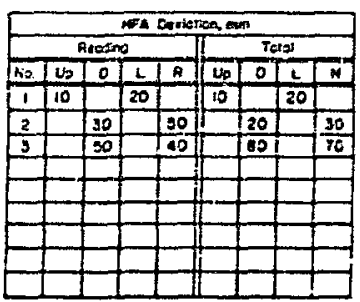

Hond Colaciotion

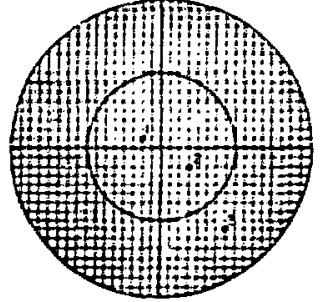

Hend Piof aide of the outer houging of a suetion of the hole-forming assembly (HFA). This can be nccompliojed by diverting the inlet-ccolant Elow as shown in Fig. 22. A gravityactivated roolant-channeling valve, zotationally aligned with the stem, makes it possible to select the azinuthal location of the cooled side on the advancing housing and thus to apply directive force to the BFA from the control console. Construction and operation of such a device are outlined in Fig. 22. The gravity-activated coolantchanneling valve is an eccentrically weighted disk that is free to rotate on frictionless ball bearings withis the cuter tube of the aligament-conirol section. Thus, if the stem is rotated at the stem advancer end, the coolant-channeling valve retains its relevant position with respect to the melted hole. In addition to a passage for the inner coolant- (and debris-) return tube, the coolant-channeling valve has two ports: one, labeled $A$ in Eig. 22, is for total coolant bypass when no corrective force is required. The second passage, $B$, is used to selectively channel the coolant flow into Coolant Passage $c$ to provide an azimuthally chilled portion of the outer tube. This cooler region will tend to cause a deflection of the tube, which, in turn, will generate a moment to act on the penetrator (see Appendix).

Imnediately downstream of the coolantshanneling valve is a bulkhead with five ports. Port $A$ is for normal flow bypass and is spaced between ports $E$ and $D$, two of the

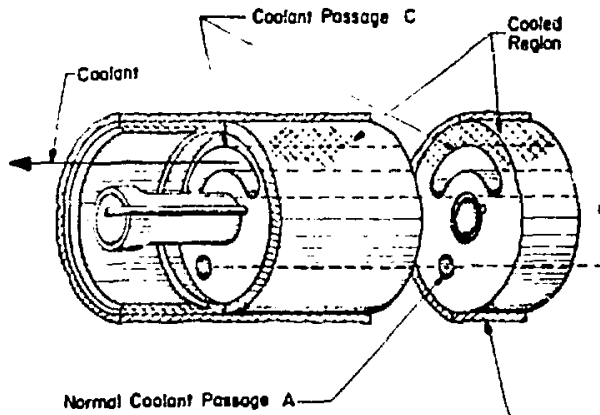

Worm Gloss LInling-

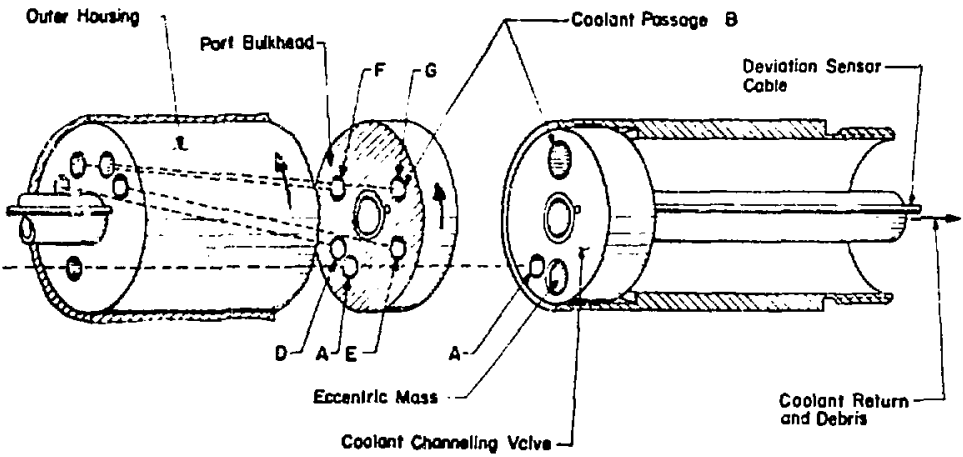

Fig. 22. Alignment control section. 
four ports (D, E, $P$, and G) spaced 90 deg apart for selective flow control. There four ports are led through the outer housing so that all four connect with coolant passage $C$. Coolant Passage $C$ extends along one side of the outer housing for a distance sufficient to produce the required turning force then coolant $1 \mathrm{~s}$ ducted through.

For normal flow bypass, the atem is rotated until port $A$ in the coolant-chruneling valve is in line with port $A$ in the bulkhead with Coolant Pasaaga $C$ racing up. This position is marked at the stem-advancer end wth a fiducial protractor clamp placed on the advancing stem. When deviation of the heated penetrator from the center line of the hole is detected and shown on the suxface display (Fig. 20), the operator car make the necessary correction. For example. if the display shows left deviation, the operator rotates the stem 90 deg to the right, so that the coolant passage, $c$, is moved to the right-hand side of the hole and Port B is alfgned with Port $G$ in the bulkhead; Pcrt A is blanked off. Differential cooling of the outer housing will turn the HFA back toward the hole center line, at which time the coolant is returned to normal bypass flow by returning the stem-position indicator at the advancer to the Passage-C up position.

other systems of alignment control can be visualized, such as having three or four equally spaced coolant passages and adjusting the coolant flow in the HFA with remotely controlied valves. The smallness of a 76-mmdiam hole and the restricted volume available for HFA control suggested the concept of a gravity-activated coolant-channeling valve for alignment control.

\section{OPERATIONS}

The components 1 isted and described in Sections III and IV will be selected or designed to be modular and interchangeable.
The GFA can be assembled in any of the following configurations:

- Consolidating penetrator with ster central12 $\mathbf{s}$.

- Consolidating penetrator with deviation indicator and sten centralizers.

- Congolidating penetrator with deviation indicator, stem centralizers, and allgnment-control section (ACS).

- Extruding penetrator with any of the above options.

The correct HFA will be selected to fit the Individual job requirements, including the desired accuracy in the location of the melted hole. When maximum accuracy is desired, the center line of the hole can be established by conventional methods, e.g., by usual land-surveying as indicated in Pig. 23.

The stem advancer and support equipment are then moved to the starting point of the hole. The HFA (and a section of stem) are clamped in the stem-gripping clamps. A transit and stadia rods are used to check alignment of the bearing and the inclination angle determined by the survey. Adjustments are made by blocking and woiging the stem-advancer base. The support equipment is located as the terrain permits, with the control consoie close to the stem advancer. All equipment is started, operated, and serviced according to the manufact ${ }^{\cdots}-r^{\circ} s$ instructions. Service lines are attached, and melting of the hole is started.

stem-gripping clamps on the pairs of advancing hydraulic cylinders are used alternately: While one clamp is advancing, the other is retracting in preparation for a continuous advancing stroke. All functions related to advancing and retracting the stem and the HFA are controlled from the console, with the exception of addiry (or removing) additional stem sections.

When additional stem is required, the operator:

- Reduces power and coolant flow to zero. 


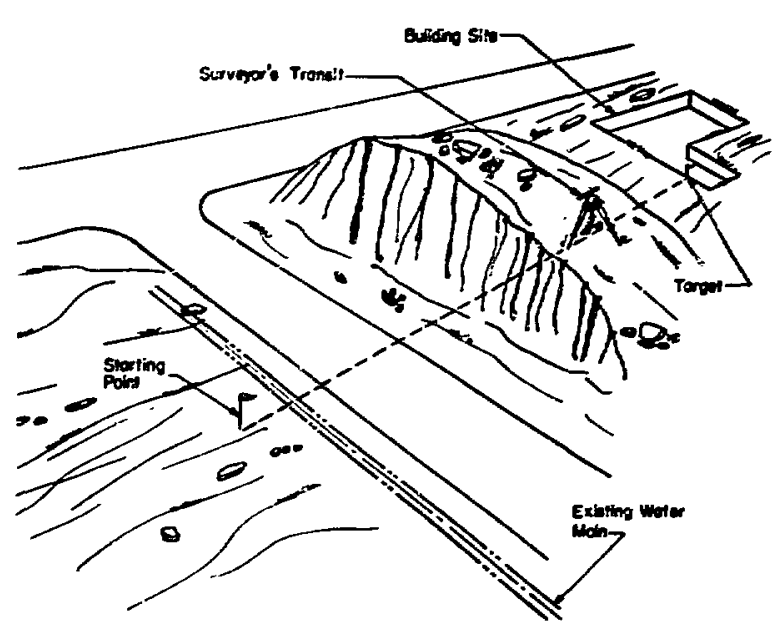

Fig. 23. Establishing the hole center line.

- Stops advancing pregsure and releases the rear stem-advancing clamp, returning this clamp to the full-out position.

- Ix l eases bladder pressure in quickdisconnect service head (QDSH).

- Slips off QDSH and unplugs slgnal leads.

- Adds stem section and tightens connection after plugging-in signal leads.

- Slips on QDSH, replugs signal leads to console and repressures bladder.

- Raises power and coolant flow to previous values.

- Regrips stem and applies previous load.

The stem is retracted (when the hole is finished or for any other reason) with the following steps; the operator:

- Reduces stem load to zero.

- Reduces power to zero.

- Reverses thrust load to retract mode.

- Maintains coolant flow until the stem pulls freely (stem drag only).

- Shuts off retraction force.

- Reduces coolant flow to zero and removes QDSH.

- Pulls out stem until the next stem connection is accessible. Loosens and unscrews connection.

- Unplugs signal leads and racks stem section.
- Continues the two previous steps until HFA is out of hole.

- Secures all equipment.

If required, the hole can then be surveyed by visual observation or instrumentation to evaluate straightness, glass-casing thickness, etc.

\section{CONCLUSIONS AND DISCUSSION}

The development of small-diameter Subterrene rock-melting penetrators has reached the stage where the design of a 75-mu (3-in.) diam system for forming horizontal, glasslined holes is possible. Contacts with ut1lity companies and requests for information from industrial firms have indicated the need for such a device.

A comprehensive development program would have to address two major areas:

- The developnent of an alignmentcontrol subsystem.

- The conduct of an economic study and a market survey.

A must attractive feature of horizontal hole-melting Subterrene systems is the capability of varying the accuracy of hole straightness to match job requirements. This is achieved by including or omitting the appropriate sections in the hole-forming assembly.

The information and experience gained from the development and commercialization of the horizontal hole-melting system will be of value to other subterrene system developments. The benefit derived can be antiripated to be:

- Field data on service life and rellability of components, particularly penetrators.

- Extension of the technology to the melting of holes with curved paths.

- Experience that will lead to horizontal hole-melting systems with increased diameter and range.

- Adaptation of the perfected alignment-control scheme to vertical hole-melting systems. 
The successful development of the horizontal, smal1-diameter melting system can contribute significantly to further developments in subsequent sibterrene programs. This influence is stown schematically in Fig. 24. In addition to valuable experience and direct data on service iife and reliability obtained in commercial applications, the effort will help in forning a scientific and engineering basis for design and optimization of subsequent devices. The very smal1-diameter melting penetrators isee Fig. 25 for an early prototypel can find uses such as punching holes in concrete cir masonry walls, but difficult miniaturization problems will need to be solyed if long holes are to be made. In addition, the experience with 75-mm-diam units will

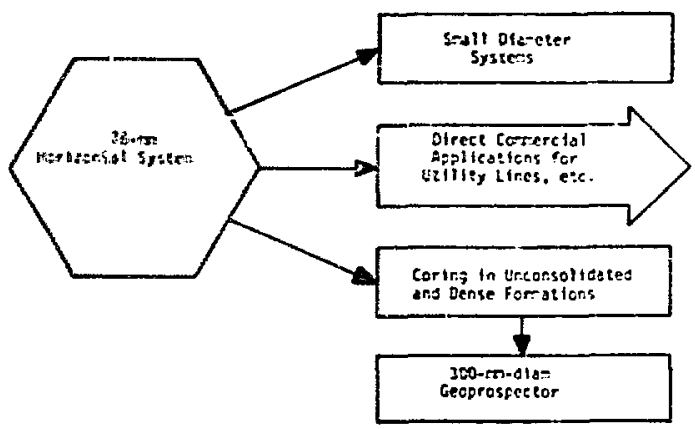

Eig. 24. Effect of 75-mm-diam horizontal Subterrene system on sibsequent research and development. contribute to the development of a Geoprospector, ${ }^{14}$ illustrated in Fig. 26, and will offer early inputs to the solutions of position sensors and guidance problems.

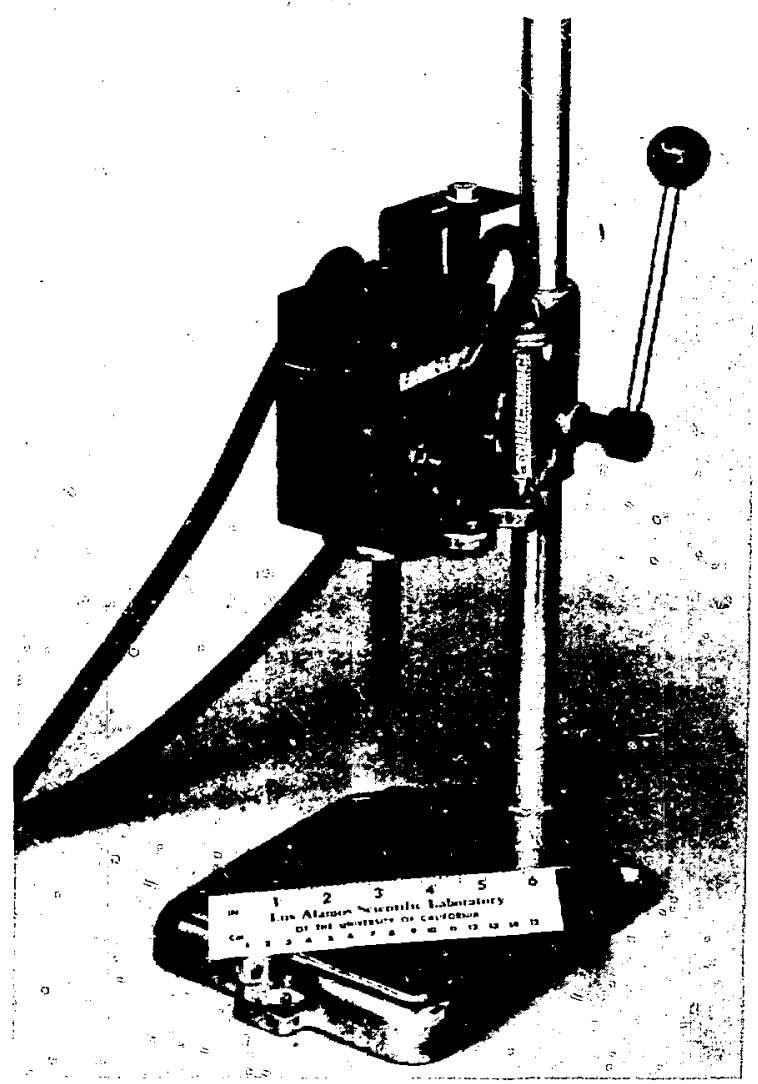

Fig. 25. Early prototype of 10-mm-diam rock-melting subterrene.

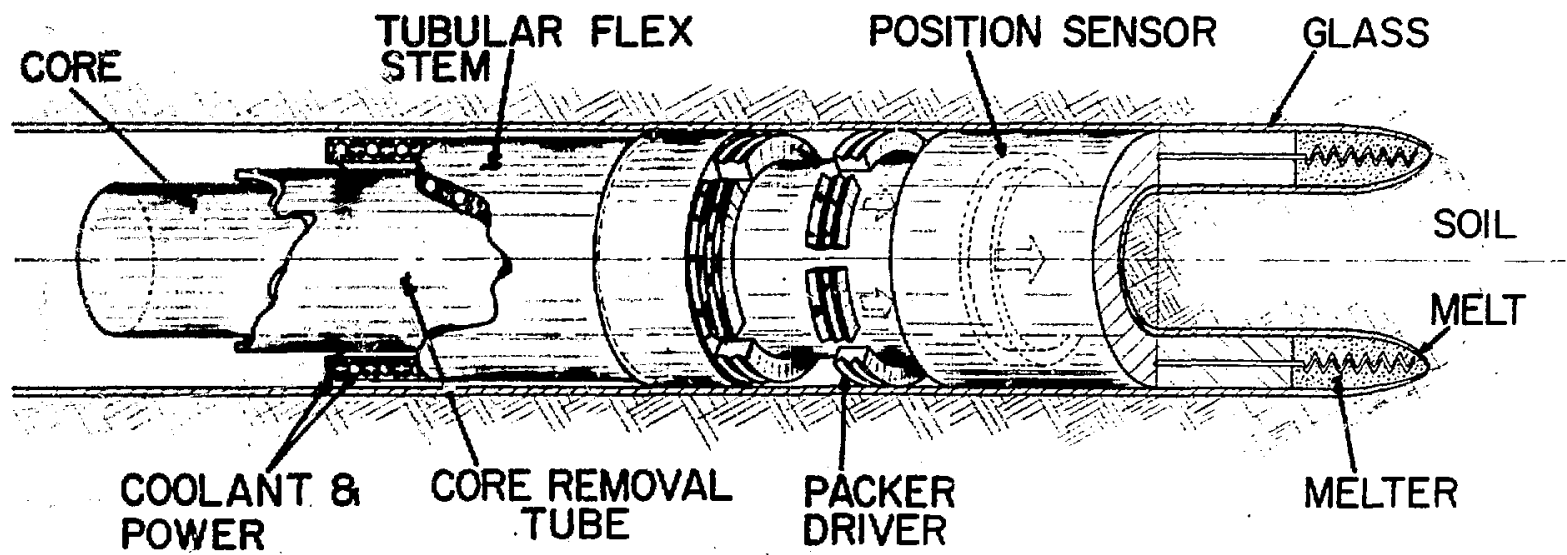

Fig. 26. Coring Geoprospector with position sensor and directional guidance systems capability. 
1. E. S. Robinson, R. M. Potter, B. B. McInteer, J. C. Rowley, D. E. Armstrong, R. L. Mills, M. C. Smith, Editor, "A Preliminary Study of the Nuclear Subterrene", Los Alamos Scientific Laboratory report LA-4547 (April 1972).

2. J. W. Neudecker, "Design Description of Melting-Consolidating Prototype Subterrene Penetrators," Los Alamos Scientific Laboratory report LA-5212-MS (February 1973).

3. R. E. Williams and J. E. Griggs, "Use of the Rogk-Melting Subterrene for Formation of Drainage Holes in Archeological Sites," Los Alamos Scientific Laboratory report LA-5370-MS (August 1973).

4. R. G. Gido, "Description of Field Tests for Rock-Melting Penetration," Los Alamos Scientific Laboratory report LA-5213-MS (February 1973).

5. J. W. Neudecker, A. J. Giger and D. E. Armstrong, "Design and Development of Prototype Universal Extruding Subterrene Penetrators," Los Alamos Scientific Laboratory report LA-5205-MS (March 1973).

6. R. E. Willlams, "Development of a Modularized Mobile Rock-Melting Subterrene Demonstration Unit," Los Alamos Scientific Laboratory report LÄ-5209-MS (March 1973).

7. D. L. Sims, "Identification of Potential Applications for Rock-Melting subterrenes," Los Alamos Scientific Laboratory seport LA-5206-MS (February 1973).

8. James Paone, "Horizortal Holes for Underground Power Lines," Proc. Tunnel and Shaft Conf., Minneapolis, MN, May 15-17, 1968, pp 93-113.

9. R. L. Waters, The Electro-Mechanics Company, P. O. Box 1546, Austin, TX, letter communications, April 1973.

10. Sperry-Sun Well Surveying Catalogue 723, "Magnetic Steering Tool", p. 4049. Sperry-Sun Well Surveying Co., P. O. Box 36363, Houston, TX 77036

11. Humphrey, Inc. Bulletin FG-1270, "Surveyor Bore Hole Directional Systems", Humphrey, Inc., 2805 Canon St., San Diego, CA 92106

12. C. Ishan, Scientific Drilling Control, 4040 Campus Drive, Newport Beach, $C A$, personal communication, April 1973.

13. L. A. Rubin, "New Survey Systems for Drillins," Telcom, Inc., McLean, VA 1971.

14. J. W. Neudecker, "Conceptual Design of a Coring Subterrene Geoprospector", Los Alamos Scientific Laboratory report in preparation. 


\section{ANALYSIS OF RROPOSED ALIGNMENT CONTROL SCHEME}

The parameters affecting the design and performance of the ailignment control section (ACS) proposed in the main body of the report can be derived by reference to Fig. $A-1$. The temperature difference established across the diameter of the ASC by the diverted coolant will induce a curvature in the housing given by

$$
\frac{1}{\rho}=\frac{\bar{a} \Delta T}{D},
$$

if the unit is free to deflect [Fig. $A-1$ (a)], where $\Delta I=$ effective temperature difference;

$$
\begin{aligned}
& p=\text { radius of curvature } \\
& \ddot{c}=\text { mean coefficient of thermal } \\
& \text { expansion } \\
& D=\text { diameter of the housing. }
\end{aligned}
$$

Typical values for the projected design and materials are:

$$
\begin{aligned}
\bar{\alpha} & \cong 6.0 \times 10^{-6}, \mathrm{~K}^{-1} \\
\mathrm{D} & =75 \mathrm{~mm} \equiv 0.075 \mathrm{~m} \\
\Delta T & =100 \mathrm{~K} .
\end{aligned}
$$

The curvature and radius of the deflected path are

$$
\begin{aligned}
& \frac{1}{\rho}=\frac{6.0 \times 10^{-6} \times 10^{8}}{0.075}=0.008 \mathrm{~m}^{-1} \\
& \rho=125 \mathrm{~m} .
\end{aligned}
$$

Therefore, if the length, $I$, of the ACs unit is $1.0 \mathrm{~m}$, the derivation at the end of the unit will be given by

$$
\Delta=\frac{\bar{\alpha} \Delta \mathrm{T}}{2 \mathrm{D}} \quad=0.0033 \mathrm{~m} \equiv 3.3 \mathrm{~mm} \text {. }
$$

If the ASC is initially rigidly fixed by a centralizer section at one end and the penetrator at the other end, Fig. A-l(b), it will exert a moment given by

$$
M=\frac{E I}{\rho},
$$

where

$$
\begin{aligned}
& E= \text { elastic modulus of the material } \\
& \text { from which the ACS is constructed } \\
& I=\text { area moment of the ACS cross } \\
& \text { section. }
\end{aligned}
$$

Taking $E=207.0 \mathrm{GPa}\left(30 \times 10^{6} 1 \mathrm{~b}_{\mathrm{f}} / \mathrm{in.}{ }^{2}\right)$, the data above, and combining Eqs. $(A-1)$ and $(A-2)$, the moment $(M)$ and induced stress $(\sigma)$ are:

$$
\begin{aligned}
& M=2.6 \times 10^{3} \mathrm{~N} \cdot \mathrm{m}\left(2.27 \times 10^{4} \mathrm{in} .1 \mathrm{~b}_{\mathrm{f}}\right) \\
& \sigma=62 \mathrm{MPa}\left(9.0002 \mathrm{~b}_{\mathrm{f}} / \mathrm{in} .{ }^{2}\right) .
\end{aligned}
$$

This moment is of sufficient magnitude to induce the required path deviation while generating only low stresses in the holeforming assembly.
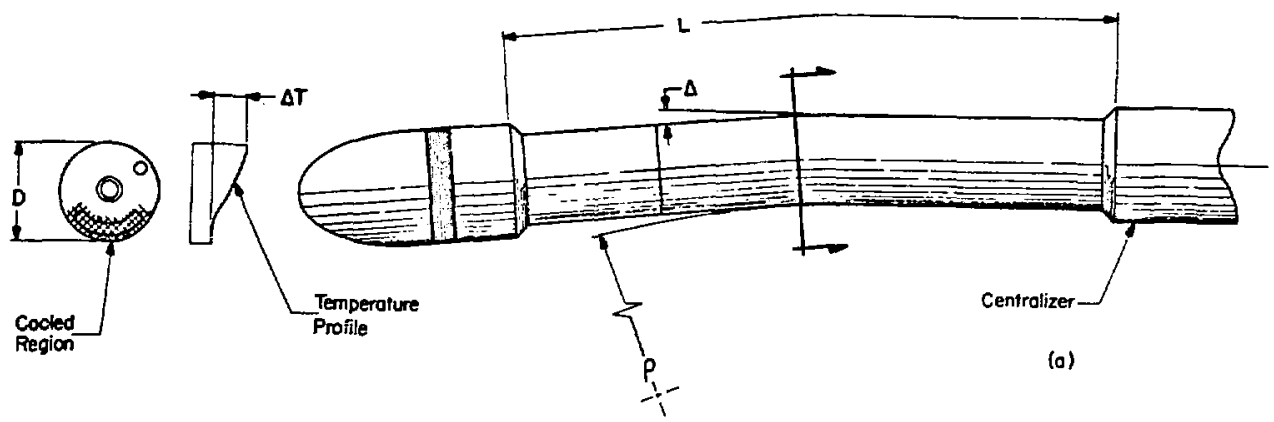

(a)
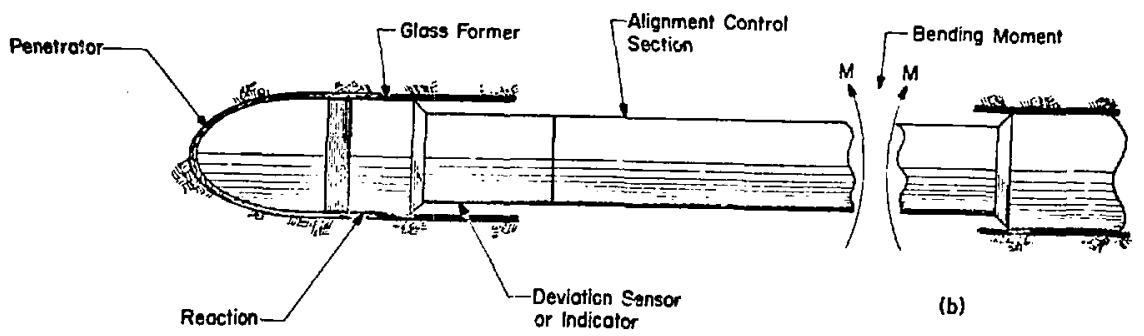

Fig. A-1. Proposed alignment control scheme. 